\title{
Severe Chronic Active EBV Infection
}

National Cancer Institute

\section{Source}

National Cancer Institute. Severe Chronic Active EBV Infection. NCI Thesaurus. Code C162687.

A severe form of chronic Epstein-Barr virus infection characterized by continued intermittent fever, lymphadenopathy, thrombocytopenia, lymphocytopenia, neutropenia, polyclonal gammopathy, and greatly elevated titers for antibodies to EBV-related antigens. 